\title{
A PRACTICAL THERMOPNEUMATIC VALVE
}

\author{
Charles Grosjean, Xing Yang*, and Yu-Chong Tai \\ Caltech Micromachining Lab, Caltech EE 136-93, Pasadena, CA 91125, USA \\ * Now at ACLARA BioSciences Inc., 3906 Trust Way, Hayward, CA 94545, USA
}

\begin{abstract}
Previously, we reported a thermopneumatic silicone rubber membrane valve [1]. This valve combined thermopneumatic actuation with a low modulus silicone rubber membrane. However, the leakage of the working fluid through the membrane rendered the valve unusable in a day or two. Here, we present extensive optimization and characterization of a redesigned valve structure. This new design has a suspended membrane heater optimized for low power consumption, a composite silicone rubber on Parylene membrane that exhibits low permeability and modulus, and a novel valve seat designed to improve sealing in the presence of particles. The valve has been extensively characterized with respect to power consumption vs. flow rate and transient response. Very low power consumption has been demonstrated. For example, less than $40 \mathrm{~mW}$ is required to switch a one slpm nitrogen flow at 33 psi. Water requires close to $100 \mathrm{~mW}$ due to the cooling effect of the liquid. The previously reported valve required more than $280 \mathrm{~mW}$ to switch a similar air flow.
\end{abstract}

\section{INTRODUCTION}

A number of active MEMS valves have been demonstrated using thermal [2], electromagnetic [3], pneumatic $[4,5]$, and thermopneumatic [6] actuation. In general, these devices consist of a stationary valve seat and a deflectable diaphragm. Given the similar underlying structure, differences center on geometry, the actuation mechanism, and the membrane material. Low power, small size, and relatively large flow rates are desirable characteristics for a microvalve. To achieve high flow rate, a large gap is required between the seat and sealing membrane along with fairly large inlet/outlet holes. If a rigid membrane material is used, the size of the structure must be fairly large, or very high force must be used to deflect the membrane to the valve seat. If a rigid material is used for the valve seat and membrane, high force is required to ensure that the diaphragm conforms well to the

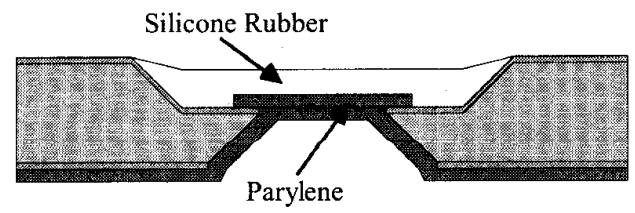

Figure 1. Composite Silicone/Parylene Membrane. sealing surface. Also, defects on either surface or particles can hinder effective sealing. As a result, high power is required for operation. Most actuators with the required force and displacement characteristics have fairly high power consumption and thermopneumatic actuation can be very poor due to the inefficiency of a simple resistive heater on a solid silicon or glass substrate in heating the working fluid.

Our approach has concentrated on the use of low modulus membrane materials to reduce the force required for closing the valve and improving sealing on the seat, and low power heater designs to reduce heat lost to the environment. Previously, we reported a valve using silicone rubber as a membrane, a simple gold resistor on glass heater, and a planar valve seat. Large deflections were obtained using thermopneumatic actuation and a variety of working fluids, but power consumption was still high. In addition, silicone rubber is permeable to the working fluid resulting in very short working lifetimes. However, silicone rubber is fairly robust and provides very effective sealing. To remedy these problems, we investigated materials that could be used to form a composite membrane with low modulus and vapor barrier properties. At the same time, we experimented with several heater designs in an effort to reduce heat lost to the substrate and a new valve seat design to improve sealing and particle resistance.

\section{DESIGN AND FABRICATION}

\section{Composite Membrane}

The requirements for the valve membrane chip were small size, impermeability to the working fluid, large deflection, and an adhesive compatible surface for bonding the seat chip. Parylene $\mathrm{C}$ forms an effective vapor barrier and load deflection tests [7] were performed to determine the Young's modulus of MRTV1 [1] silicone rubber $(0.51$ MPa) and Parylene C [8] (4.5 GPa) which are orders of magnitude smaller than silicon or silicon nitride. To keep the membranes soft, a very thin Parylene layer was used compared to the silicone rubber layer. Also, the Parylene was kept next to the working fluid chamber to prevent adsorption in the silicone rubber. The membrane was built in a recessed silicon cavity as shown in Fig. 1 using a molding process for the silicone rubber (similar to the process reported in [1]) to accommodate a bonding frame 


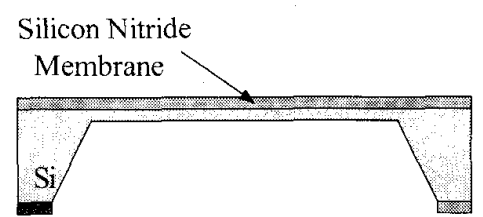

KOH Etching

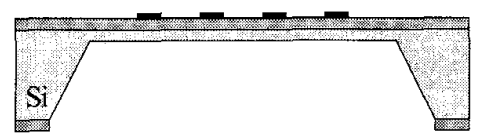

$\mathrm{Cr} / \mathrm{Au}$ Deposition and Patterning

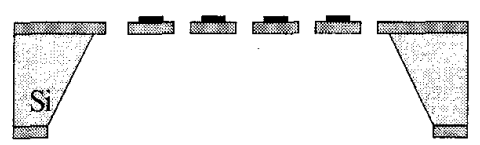

Silicon Nitride Patterning

Figure 2. $S i_{x} N_{y}$ membrane heater fabrication process.
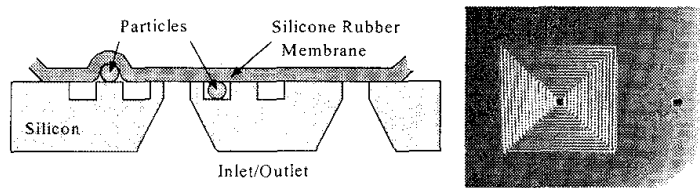

Figure 3. New valve seat design with sealing grooves.

around the membrane. A $<100>$ wafer is oxidized, patterned, and etched from both sides in $\mathrm{KOH}$ to form $235 \mu \mathrm{m}$ deep cavities on each side of the wafer leaving a 50 $\mu \mathrm{m}$ thick silicon membrane. The top cavity is $5.0 \times 5.0 \mathrm{~mm}$ and serves as a mold for the silicone. The bottom cavity serves as part of the reservoir for the working fluid and defines the size of the composite membrane which is $2.7 \times$ $2.7 \mathrm{~mm} . \mathrm{Si}_{x} \mathrm{~N}_{y}$ is deposited and patterned and the thin silicon membrane is removed in $\mathrm{KOH}$ leaving a freestanding $\mathrm{Si}_{\mathrm{x}} \mathrm{N}_{\mathrm{y}}$ membrane. A $2 \mu \mathrm{m}$ layer of Parylene $\mathrm{C}$ is deposited and patterned on the bottom of the cavity, followed by the molding of MRTV1 silicone into the cavity. Surface tension, shrinkage, and the adhesion of the uncured silicone to the squeegee blade form a depression in the cured silicone layer which forms the valve chamber. The backside nitride is removed by RIE and another $2 \mu \mathrm{m}$ layer of Parylene $\mathrm{C}$ is deposited on the backside to strengthen the edge of the membrane and seal the possible leakage interface between the first layer and the substrate.

\section{Suspended Heater}

For improved thermal isolation, a new heater was fabricated on a suspended $\mathrm{Si}_{\mathrm{x}} \mathrm{N}_{\mathrm{y}}$ membrane formed by $\mathrm{KOH}$ etching. Heat that would have been lost to the surroundings through the substrate is now radiated throughout the working fluid as the heater is suspended in the middle of the chamber. As shown in Fig. 2, the heater is fabricated by $\mathrm{KOH}$ etching a silicon frame with a free-standing $0.5 \mu \mathrm{m}$ $\mathrm{Si}_{\mathrm{x}} \mathrm{N}_{\mathrm{y}}$ membrane. Then a $0.5 \mu \mathrm{m} \mathrm{Cr} / \mathrm{Au}$ layer is evaporated

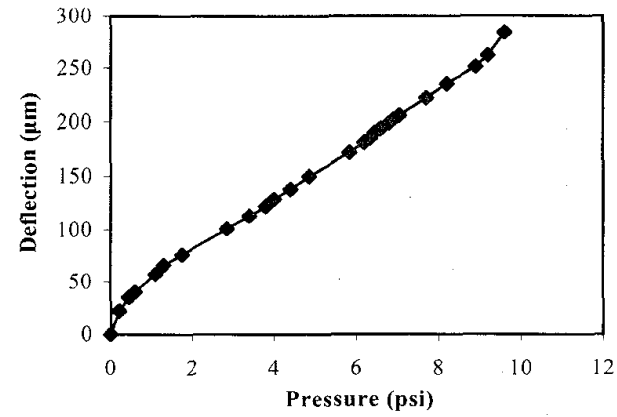

Figure 4. Pressure vs. deflection for composite membrane.

and defined to define the heater. Finally, an array of $200 \mu \mathrm{m}$ holes are etched in the membrane to equalize pressure across the membrane during operation.

\section{Valve Seat}

Originally, this consisted of a glass die with two mechanically drilled holes for the inlet/outlet. The finish of the holes was poor due to chipping and the alignment was problematic as they were manually drilled. The new valve seat is fabricated in silicon with anisotropically etched inlet and outlet holes and a series of $30 \mu \mathrm{m}$ deep concentric grooves etched with RIE around one hole to facilitate redundant seals and particle entrapment as shown in Fig. 3.

\section{COMPONENT TESTING}

\section{Thermopneumatic Actuator}

Load deflection testing was performed on a composite membrane and is shown in Fig. 4. The designed valve gap is $60 \mu \mathrm{m}$ and only one psi is required to achieve that level of deflection demonstrating that the composite membrane is very soft. A membrane was assembled with a heater and backing plate to form a thermopneumatic actuator for the

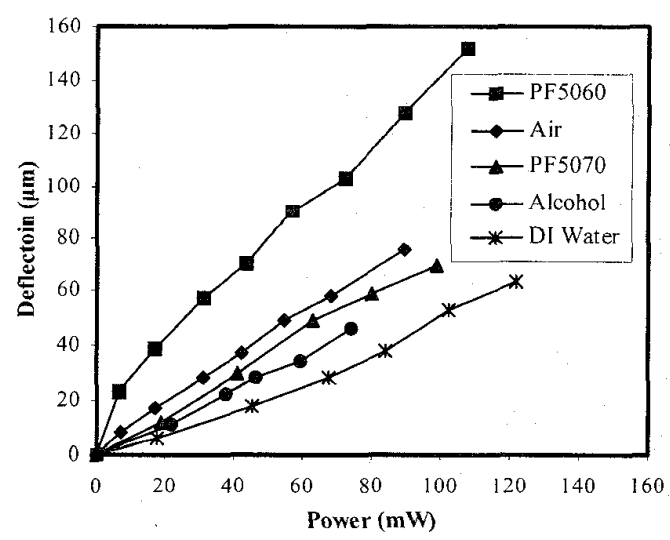

Figure 5. Power vs. deflection for thermopneumatic actuation using several different working fluids. 


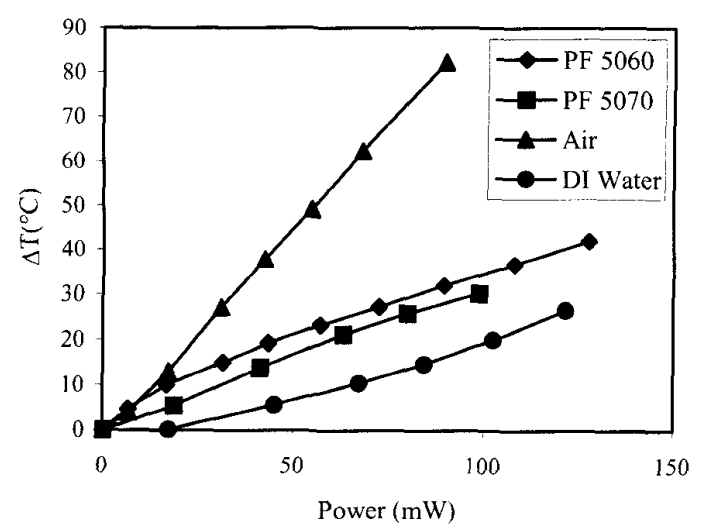

Figure 6. Power vs, approximate $\Delta T$ on heater surface.

purpose of studying steady-state and transient performance. The cavity formed by the membrane die and heater die was filled with a variety of liquids to determine the actuation achievable by thermal expansion and vapor pressure change. Because of the high temperatures achievable with the membrane heaters, an air bubble in the chamber would often lead to overheating and permanent damage to the Parylene membrane. Fig. 5 shows the results of power vs. deflection for cavities fully filled with water, Fluorinert ${ }^{\mathrm{TM}}$ (PF-5060, PF-5070), isopropanol, and air. Actuators with an air bubble in the cavity had higher power consumption and failed quickly due to overheating. This demonstrates that pure thermal expansion appears to be the most efficient mode of operation, especially as the ultimate deflection of the membrane is limited by the valve seat. To obtain an estimate of the temperature inside the cavity, the TCR of the gold heater was measured. By monitoring the resistance at a given power input, the average temperature on the membrane was determined. The power vs. temperature change is shown in Fig. 6 and as expected, the low thermal conductivity of air results in very high temperatures.

Transient performance was measured by driving the actuator assembly with a function generator while measuring membrane deflection with a laser interferometer. The response typically exhibits two time constants, a short one associated with heating the working liquid, and a longer

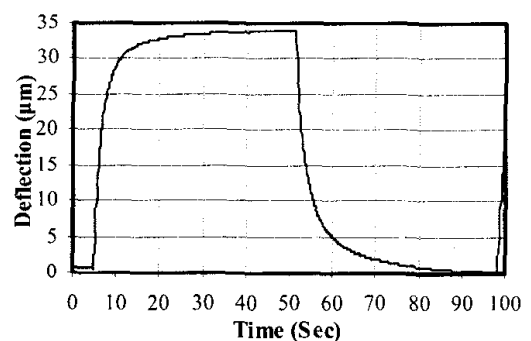

Figure 7. Transient response for PF5060 filled actuator with glass backing plate on metal heat sink.

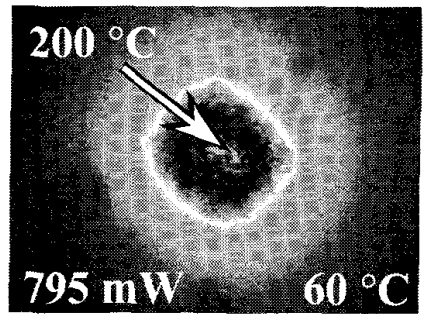

(a) Glass Substrate Heater

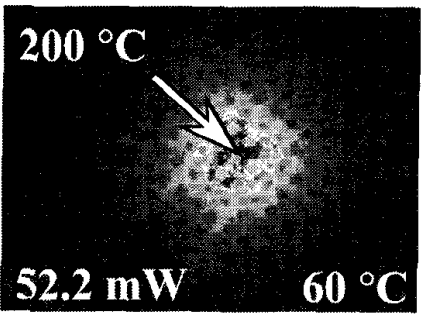

(b) $\mathrm{Si}_{\mathrm{x}} \mathrm{N}_{\mathrm{y}}$ Membrane Heater

Figure 8. 2-D measured temperature profile comparing glass to $S_{i} N_{y}$ membrane heater.

one related with the heating of the package and surroundings. A heater with good thermal insulation consumes less power, but it takes longer for the heat to dissipate resulting in a trade-off between power consumption and speed. While a valve can be closed quickly by applying a large power pulse, the opening time may be increased substantially due to the time to dissipate extra energy to the environment. Air provides the fastest time constants due to its low density, even though its thermal conductivity is fairly low compared to the liquids. Using PF-5060 as the working fluid, the time constants are $1.7 \mathrm{sec}$ and $38.2 \mathrm{sec}$ for heating, and $2.1 \mathrm{sec}$ and $37.0 \mathrm{sec}$ for cooling. The second time constant can be improved substantially by using a metal heat sink on the package to $1.5 \mathrm{sec}$ and $7.1 \mathrm{sec}$ for heating and 1.8 and $9.4 \mathrm{sec}$ for cooling as shown in Fig. 7 at the expense of increased power consumption. For faster performance at the expense of power, active cooling would be one solution.

\section{Heater Design}

An IR microscope (Infrascope ${ }^{\text {TM}}$ ) was used to compare the performance of the new suspended heater and a glass substrate heater in free air on a metal substrate. Fig. 8 shows the power required to reach $200{ }^{\circ} \mathrm{C}$ on the heater surface for the two types. The suspended heater requires much less power and the heat is far more localized resulting in less loss via conduction to the valve assembly. Simulation [9] has shown that up to $98 \%$ of the heat generated by a resistor on glass heater is lost to the substrate and surroundings. Using the composite membrane chip with a $3 \times 3 \mathrm{~mm}$ backside opening, three different heater sizes were fabricated to investigate the 


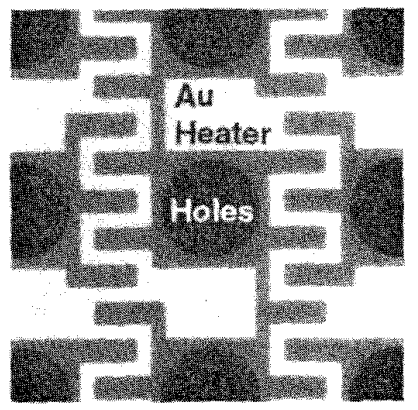

Figure 9. Medium $(2.1 \times 2.1 \mathrm{~mm}) S i_{x} N_{1}$ membrane heater with gold pads for increased surface area.

effect of heater surface area on performance. The small heater $(1.1 \times 1.1 \mathrm{~mm})$ and medium heater $(2.1 \times 2.1 \mathrm{~mm})$ shown in Fig. 9 had similar steady-state performance with the small heater taking longer to reach thermal equilibrium. The large $(2.9 \times 2.9 \mathrm{~mm})$ heater required significantly more power for a similar deflection leading to the conclusion that more power was being lost to the substrate due to the proximity of the heater to the sidewalls.

\section{Valve Sealing}

Non zero flow when the valve is closed can be a significant problem with microvalves. This can be caused by stiction of particles near the seat, defects in the structure, or poor design. Some valves use intricate seat designs to achieve high sealing force. Given the low durometer and conformability of silicone rubber, good sealing can be achieved against a flat surface even in the presence of particles as shown in Fig. 10. This property along with the new valve seat results in extremely low leakage.
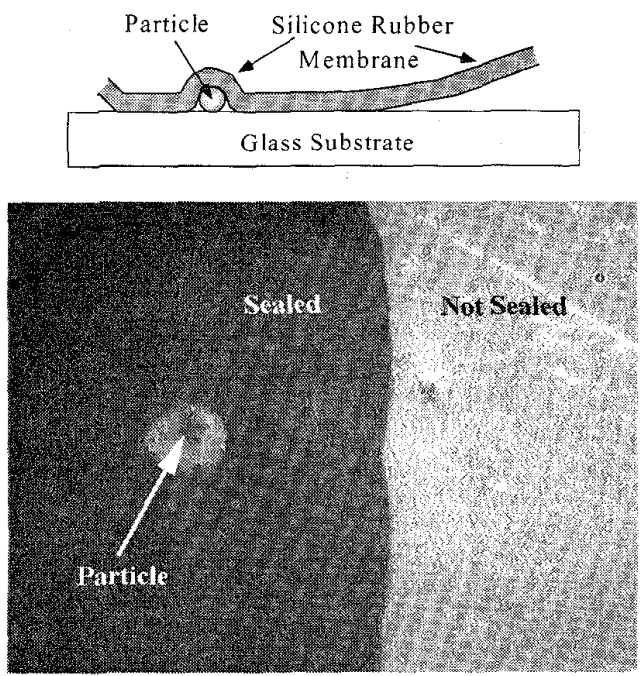

Figure 10. Silicone membrane inflated against glass plate demonstrating good sealing around a particle.

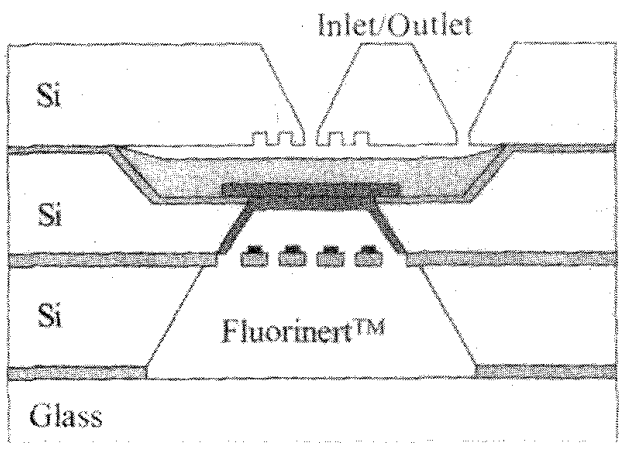

Figure 11. Cross section of assembled microvalve.

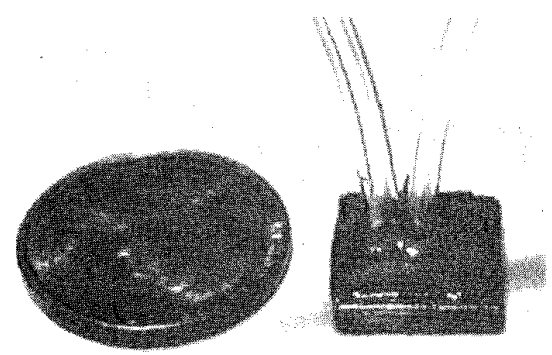

Figure 12. Valve assembly with Tygon $₫$ tubing.

\section{VALVE TESTING AND RESULTS}

Valves were fabricated by assembling valve seat, composite membrane, heater, and backing plate dies as shown in Figs. 11 and 12. Epoxy was used to bond the dies together as high temperature bonding processes can't be used with the composite membrane. The $60 \mu \mathrm{m}$ recess in the molded silicone forms the gap between the membrane and valve seat which simplifies fabrication of the latter greatly. As suggested by the thermopneumatic actuation results, all valves were fully filled with 3M PF-5060 for greatest deflection per unit power. One factor which plays a great part in the power consumption of the valve is the alignment of the seat to the membrane. Misalignment will increase the power necessary to seal the valve for a given flow as the contact area between the membrane and seat must be larger. As the valve seat is silicon, it is difficult to optically verify alignment after assembly.

Initial valve testing was performed with dry nitrogen. Variations included inlet/outlet hole size and choice of inlet ports (center or side of the seat chip). Flow testing of small and large hole size $(400 \mu \mathrm{m}$ and $600 \mu \mathrm{m}$ square respectively) valve seats confirmed the greater flow capability of the larger holes sizes, but it was determined that the increased flow was not necessary in our application, especially at the price of increased power consumption. It 


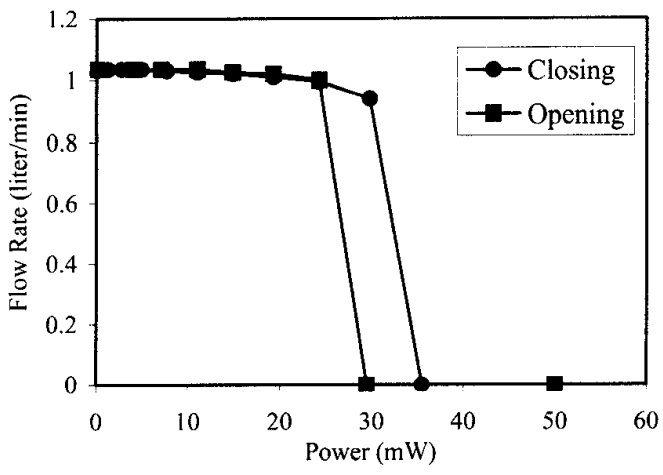

(a) nitrogen flow @33 psi, closes at $35.5 \mathrm{~mW}$

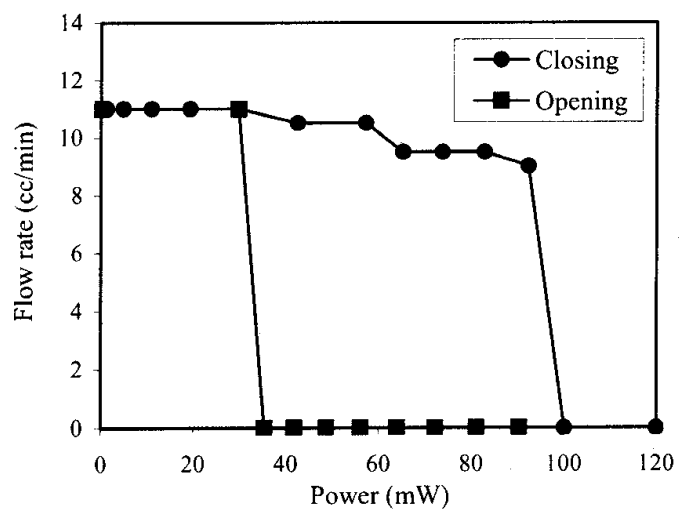

(b) water flow@32 psi, closes at $100 \mathrm{~mW}$

Figure 13. Performance for the same valve using nitrogen and water demonstrating low power consumption and large hysteresis between opening and closing due to heat lost by convection to the liquid.

was also found that valves were most efficient when the outlet was located at the center of the valve seat. Fig. 13 shows data from the same valve for nitrogen flow, and water flow at 33 psi. Simulation verifies that the major contribution to the hysteresis between opening and closing power is heat lost by convection to the liquid. This explains the much greater power required to close the valve when flowing water vs. nitrogen versus the opening power which is very similar. This is due to the greater specific heat of water vs. nitrogen. By looking at the power required to keep the valve closed, we can estimate the temperature increase inside the cavity by using the resistance of the heater, which is approximately $20^{\circ} \mathrm{C}$ above ambient.

Another data set was taken for a single valve with a wide range of inlet pressure and is shown in Fig. 14. This valve exhibits higher power consumption which is most likely due to valve seat/membrane misalignment. Of interest is the trend of increasing power consumption for lower inlet pressure. The most likely explanation of this behavior is increased contact area between the membrane

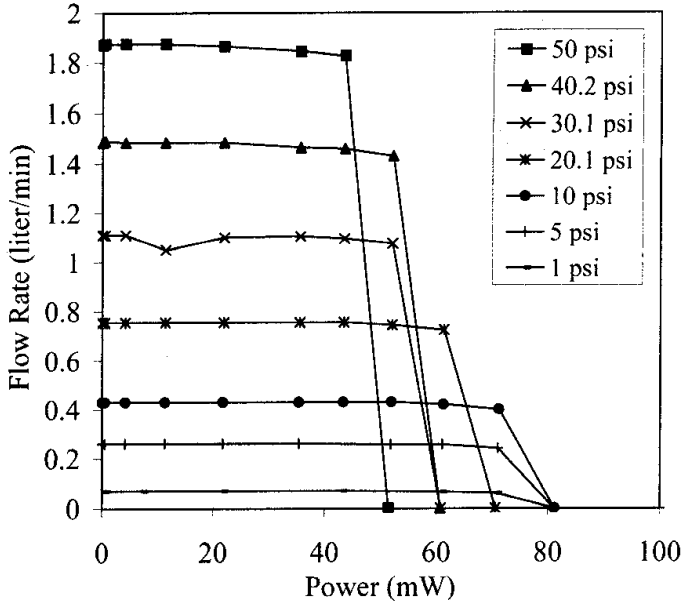

Figure 14. Family of curves for a single valve tested at various pressures for nitrogen flow.

and valve seat resulting in more heat loss by conduction through the membrane. This along with the hysteresis between opening and closing powers indicates that improved thermal insulation should be considered for the membrane, possibly by making the silicone rubber layer thicker which would not significantly affect the stiffness due to the Parylene.

\section{CONCLUSION}

A normally open low power thermopneumatic MEMS valve utilizing a composite silicone rubber/Parylene membrane has been designed, fabricated and tested. A novel suspended heater has been developed to reduce heat loss. By using a "soft" membrane with a large gap, and thermopneumatic actuation, high flow rates are achievable while still keeping power consumption low. A new valve seat has been developed that complements sealing properties of the silicone membrane to reduce the leak rate of the valve when closed. The steady state and transient behavior of the thermopneumatic actuation have been studied and an optimum working fluid and heater design have been identified. The valve shows very low power consumption. A one slpm nitrogen flow with an inlet pressure of 33 psi can be controlled with less than $40 \mathrm{~mW}$. A water flow at similar pressure requires $100 \mathrm{~mW}$ due to additional heat lost by convection. The valve structure measures $8 \times 8 \times 2 \mathrm{~mm}$ and satisfies the requirements of small size, low power, and acceptable flow rate. Furthermore, the design of the valve seat in conjunction with the flexible silicone membrane provides good sealing.

\section{ACKNOWLEDGEMENTS}

This work is supported by the DARPA MICROFLUMES program under Naval Ocean Systems 
Center Contract N66001-96-C-83632. The authors would like to thank Ms. Ellis Meng for help with testing, Dr. Qiao Lin for simulation, and Mr. Trevor Roper for assistance with fabrication.

\section{REFERENCES}

[1] X. Yang, C. Grosjean, Y.-C. Tai, and C.-M. Ho, "A MEMS Thermopneumatic Silicone Membrane Valve," Proceedings of IEEE the $10^{\text {th }}$ Annual International Workshop on Micro Electro Mechanical Systems, Jan 26-30, 1997, Nagoya, Japan, pp. 114-118.

[2] P. W. Barth, "Silicon Microvalve for Gas Flow Control," Digest of Technical Papers, Vol. 2, The $8^{\text {th }}$ International Conference on Solid-State Sensors and Actuators, June, 1995, pp. 276-279.

[3] C. Ahn, T. Henderson, W. Heineman, and B. Halsall, "Development of a Generic Microfluidic System for Electrochemical Immunoassay-Based Remote Bio/Chemical Sensors," Proceedings of the $\mu T A S$ ' 98 Workshop, October 13-16, 1998, Banff, Canada, pp. 225-230.

[4] L. Bousse, E. Dijkstra, and O. Guenat, "High Density Array of Valves and Interconnects for Liquid Switching," Technical Digest of the 1996 Solid State Sensor and Actuator Workshop, Hilton Head Island, SC, June 3-6, 1996, pp. 272-275.
[5] C. Vieider, O. Ohman, and H. Elderstig, "A Pneumatically Actuated Microvalve with a Silicone Rubber Membrane for Integration with Fluid Handling Systems," The $8^{\text {th }}$ International Conference on SolidState Sensors and Actuators, June, 1995, pp. 284-286.

[6] M. Zdeblick, R. Anderson, J. Janskowski, B. KlineSchoder, L. Christel, R. Miles, and W. Weber, "Thermopneumatically Actuated Microvalves and Integrated Electro-fluidic Circuits," Technical Digest of the 1994 Solid State Sensor and Actuator Workshop, Hilton Head Island, SC, June 13-16, 1994, pp. 251255.

[7] O. Tabata, K. Kawahata, S. Sugiyama, and I. Igarashi, "Mechanical Property Measurements of Thin Films Using Load Deflection of Composite Rectangular Membranes," Sensors and Actuators, 20 (1989) pp. 135-141.

[8] X. Yang, "Micromachined Silicone Rubber Membrane Valves for Fluidic Applications," Ph.D. Thesis, California Institute of Technology, p. 124.

[9] P. L. Bergstrom, J. Ji, Y.-N. Liu, M. Kaviany, and K. D. Wise, "Thermally Driven Phase-Change Microactuation", Journal of Microelectromechanical Systems, Vol. 4, No.1, 1995, pp. 10-17. 